ERRATUM

\title{
Off-label rhBMP-2 use in pediatric spine deformity surgery
}

TO THE EDITOR: We made an error in our response to a Letter to the Editor, "Off-label rhBMP-2 use in pediatric spine deformity surgery," published in the May 2015 issue (J Neurosurg Pediatr 15:546, 2015). We stated, “. . in a study by Mazur et al., ${ }^{2}$ of the 127 pediatric procedures included, 20 (15.7\%) resulted in pseudarthrosis and required revision surgery."

This was incorrect. In that study, pseudarthrosis did not occur in 20 cases $(15.7 \%)$. Rather, what we should have stated was the following:

. . . in a study by Mazur et al., ${ }^{2}$ of the 127 pediatric procedures included, there were 20 reoperations with 5 infections, 12 early hardware failures, 2 late pseudarthroses, and 1 other.

We regret this error, and we appreciate having been given the opportunity to correct it. The text has been corrected online as of September 25, 2015.

Andrew Jea, MD

Texas Children's Hospital, Baylor College of Medicine, Houston, TX

INCLUDE WHEN CITING

Published online September 25, 2015; DOI: 10.3171/2015.7.PEDS14654a.

(cAANS, 2015 